\title{
Development and Reflection of POPS(Privately Owned Public Space) in New York City
}

\author{
${ }^{a}$ Y. SHI, ${ }^{\mathrm{b}}$ L. ZHOU \\ ${ }^{a}$ School of Architecture, South China University of Technology; State Key Laboratory of Subtropi- \\ cal Building Science, South China University of Technology, Guangzhou, Guangdong, China \\ 13802979189@126.com \\ ${ }^{b}$ School of Architecture, South China University of Technology, Guangzhou, Guangdong, China \\ 331454795@qq.com
}

\section{KEYWORD:POPS; Zoning; Publicness; New York City}

ABSTRACT: Planning and management of POPS by New York City government has experienced a process from being extensive and loose to meticulous and strict, which possesses 60 years of experience hitherto. This paper reviews the historical evolution of POPS in New York City, and analyzes the impact of Zoning system and urban management policy on public space form and its publicness. Furthermore, it discusses the interaction between government planning and private capital in the forming process of urban public space. Based on this, this paper tries to find out the problems and revelations in the process of city management policy.

\section{BACKGROUND OF POPS}

In countries implementing private ownership of land, when property rights is utilized to distinguish the public space property, the space which is owned by public sectors is public space, while private space is owned by private sectors. In New York City, such as education, health care, urban infrastructure and other public goods, public space used to provide by governmental public sectors. Due to the shrinking of public finance in 1950 s, public space was no longer simply provided by government, but invested, constructed and managed by public-private jointly-operated sector or even totally private sector. Although these private owned spaces provide a wide range of public use, the property right belongs to private property. Therefore, this kind of space is named as Privately Owned Public Space (hereinafter referred to as POPS)(Carmona\&, 2008). In 1950s, western urban management ideas promoted the private sector to take over governmental public functions, advocating to utilize private capital to provide public goods and public services(Webster, 2007) as much as possible. The complexity and uncertainty of the development of post modern cities also led to the decline and insecurity of a lot of traditional public spaces, forcing the public to seek a cleaner and safer place of social intercourse, which promoted the prevalence of POPS. Apart from the political, economic, cultural and other fundamental reasons, Zoning Ordinance(Killian,1998) of the United States directly bred and gave birth to POPS. Since the first implementation of zoning in 1916 in New York City of the United States, American cities have produced the largest number of POPS in the world, 530 POPSs in New York City, 60 in central San Francisco, and 30 in central Seattle, etc. Some small-medium cities in the United States, such as Austin of Texas, Nashville of Tennessee, and Tampa of Florida, strive to push their own POPS construction plans. This paper takes New York City which has the most POPSs in the world as an example to analyze the evolution of POPS and to explore its controversial issues.

\section{DEVELOPMENT OF POPS}

\section{germination period}

In early 20th Century, with the rapid development of industrialization and urbanization in America, urban space planning and control were still in an extensive state, which was in the face of various problems such as intensive high-rise buildings in urban center, shortage of open space, serious air pollution, and poor environmental quality. In order to improve the poor urban environment, New York City introduced the first Comprehensive Zoning Ordinance in 1916, namely zoning. On the basis of land property right, zoning prescribed the nature, building height and volume, as well as 
development strength of all areas under administration of government. New York City expected to create a sense of openness of urban space through the implementation of zoning and introduced more light and air(Kayden, 2000) at street level. In order to guarantee enough open space of the street, zoning combines the height of buildings and the area of the first floor of open space quantitatively. The further the frontage building away from the edge of the streets is, the higher the buildings could be. Zoning essentially utilizes the transactional economic means, that is, providing open space (public interest) to exchange for the increase in building stories (private interests). This provision creates a system foundation for the emergence of POPS.

\section{Rapid growth period}

The Zoning in 1961 proposed the concept of the floor area ratio (hereinafter referred to as FAR) for the first time, and greatly improved the strength of the development of multiple regions of New York City. The zoning in 1961 continued the idea that exchange space for construction area. It introduced the provision of bonus open space. If additional open space is provided at the first layer of the building, FAR bonus will be offered to a scale. The interchange between public space and private space is no long reflected from width of street- height of building, but adjusted through FAR which is an indicator expressing the value of lands. This directly reflects the economic characteristics of the exchange mechanism of the public and private interests. The zoning in 1961 defined two types of bonus open space. Plazas and arcades, stipulated the area, depth and height and opened to the public in New York City. Afterwards, more types of bonus open space were gradually defined, including elevated plaza, through block arcade, covered pedestrian space, sunken plaza and open air concourse(Kayden, 2000). This further extended the scope of bonus open space, which even included various spatial forms such as open pedestrian streets within building, commercial courtyard, and exit of metro. Thus the incentive mechanism of POPS was formally established. Viewed from the morphology point, the identification standard of bonus open space is quite simple, as long as reaching the basic requirements (depth, area, floor height, etc). That is, once above-mentioned identification standards are satisfied, developers can achieve FAR bonus according to area ratio. Moreover, bonus open space possesses great economic value. Developers all scramble for bonus open space, which facilitating the appearance of POPS in large numbers: from 1961 to 1974, 231 POPSs were constructed in New York City, including 136 plazas and 57 arcades(Kayden, 2000).

\section{Perfection period}

Due to the lack of policy management, many POPSs in New York City at that time didn't possess substantive public use, which could be utilized as places for public to stay and rest. More than 50\% POPSs constructed in 1960s and 1970s lacked attractiveness to the public, and even rejected the utilization by the public(Smithsimon, 2008). In view of all kinds of problems in reality, New York City revised the provision of bonus open space of zoning from 1975 to 1977 . The new provision was significantly reformed in three aspects. Firstly, in the aspect of design standard, the new provision formulated six principles of judgment including orientation, quantity, shape, proportion, vertical, and barrier-free facilities. Secondly, in terms of facilities, the new provision offered a series of mandatory requirements, including the number of seats on urban square, greening requirements, lighting, dustbin, flooring, and nameplate. It encouraged the buildings around the square to provide commercial facilities so as to enhance the vitality of the square. Thirdly, as for the examination and approval procedures, the new provision abolished the setting of excussion. Developers must submit the city square design plan to the Planning Bureau. Upon review of compliance with design standards, and licensure, developers apply to start working to the Bureau of Construction with the license(Kayden, 2000). The new regulations also developed a margin system: Developers must prepay margin to the municipal government to ensure that the square could provide necessary facilities and appropriate management after the completion. The reform in 1975 was a correction of the previous unreasonable incentive policy. It improved the threshold of the construction POPS through the development of a series of design standards and enhance management on POPS by the planning departments. These corrections promoted the material quality of later POPS in general. POPS management has experienced some amendments in succession, such as reducing the bonus amount of volume of FAR and ensuring public safety. The number of public spaces in New York City has steadily increased under control. 


\section{PROBLEMS AND REFLECTIONS ON THE DEVELOPMENT PROCESS OF POPS}

Since POPS incentive mechanism was established in 1961, the planning management on POPS had experienced a process from being extensive and loose to meticulous and strict. POPS construction also experienced the process from vigorous growth in 1960s and 1970s to current stability. In half a century, more than 530 POPSs has been increased in New York City. However, In addition to the number, to what extent could POPS design and management guarantee the requirements on accessibility, openness, diversification of public use of space? Whether its current planning and supervision mechanism can effectively protect the public interest? These problems constitute the reflection on the publicness of POPS.

\section{Extensive growth of POPS}

Due to the imperfection of initial policy, developers could obtain FAR bonus in accordance with the law as long as the basic requirements of the public space were achieved, avoiding government approvals. In the meantime, the introduction of more types of bonus open space allowed developers to apply FAR bonus in various items, regardless of the open degree of space or whether the publicness really satisfied the needs of the public. A large portion of space was only to satisfy the form of open space in provisions. Due to the deficiency in clear provision on practical use of bonus open space, many POPSs were just empty and monotonous square. More developers toot POPS as a tool for exchanging FAR, while neglecting the spatial quality. Due to the lack of genuine public functions, many space become the place breeding drug trafficking, pornography, and graffiti behaviors(Kayden, 2000). After prevailing for a time, POPS aimed at exchanging area for public interest became the real portrayal of private interest maximization, and nominal public interest.

\section{Privatization of POPS}

However, since squares were allowed to close at night after 1996, many POPSs set gates and fences. Planning and management departments don't specify the appropriate scale and form of such obstacles, or whether these barriers should be removed in the daytime. Therefore, a large amount of POPSs are surrounded by crude fences, with an iron gate open in the daytime. This not only reduces the openness and accessibility of public space, but also expresses a sense of personal territory. This type of space is named as fortressed environments(Nemeth, 2009) by some scholars. They are derived from the congenital guard and rejection to the public interest by private capital. Some facilities within the POPS are often used to reinforce the private property of the space. For example, public seating area is surrounded and covered by parapet, railing, and awning, which is separated from public streets. The accessibility of public's line of sight is weakened. Moreover, the space is restricted through flagpoles and raised terrace, the feeling of territory of private space is further intensified. Thus the space is mainly used by its owners (Lukaitous Sideris, 1996)which reduces the chance of utilization by the general public.

\section{Commercial erosion of POPS}

After 1977, commercial facilities were encouraged to establish in POPS, such as stalls, and outdoors café seats. From a positive perspective, this is conductive to increasing the vitality of public space, and avoiding the negative functions to utilized for parking and unloading. However, owners or managers of POPS would tend to excessively encroach and occupy public space for commercial purposes in order to maximize the commercial value. There exists a so-called phenomenon of café creep in POPS, namely utilizing movable tables, chairs, ropes, banners, and flags. A certain area is divided from plaza or arcade to specifically utilize for outdoor dining and other consumer functions. In fact, this potentially delivers such information that non-consumer is forbidden to enter. This is called as the commercialization of public space by some researchers. In other words, the publicness of public space has been alienated as a commodity to be bought with money. People with a strong ability to pay enjoy the privilege and priority of public space. However, the rights and interests of the people who are unable to pay are deprived or weakened(Kohn, 2004).

\section{Limit of POPS activity content}

Security management of POPS also constitutes a challenge to public space. In order to strengthen the monitoring and prevention of improper crowd and behavior, a large number of camera monitoring systems are utilized in POPS. Private capital has the discretion of management in public behavior, which has a great restriction on the publicness of space. Because POPS generally locates in crowded city center, it is easy to attract political rallies, speeches, demonstrations, religious propaganda, distributing leaflets, putting up posters and other activities. In reality, managers of POPS 
generally strictly prohibit such activities as illegality. Records of New York City indicate that the court had never supported the requests that individuals or groups required POPS to ensure the freedom expression of political or religious views. Therefore, the de-political POPS can never show nature of democracy and freedom of public space. To a large extent, it exists only as a consumption or leisure space.

\section{Reflection}

The experience of New York City shows that the rise of POPS is due to the city managers expect to exchange area for space so as to increase the open space in city. In the meantime, private developers could obtain corresponding return to achieve a win-win situation. However, the overrun of POPS in 1960s indicated that it can't be separated from the guidance of urban planning to utilize economic means to promote the construction of urban public space. Without detailed requirements on planning and design level or the precision design of the administrative examination and approval system, POPS is likely to become a tool to seek the maximization of private interests, and the minimization of public interests.

During the last 20 years, the means of FAR bonus has been widely introduced into China's urban planning and management. The government encourages private development projects to provide open space and stilt building, increase public facilities, and adopt energy-saving construction, and offers appropriate area of incentives. Therefore, In the construction of contemporary city public spaces in China, governments and city managers should draw lessons from full-blown experiences of New York City, coordinate developers with Urban management department. Refining specific norms and incentives and making clear provisions including the form, scale, size, direction, facilities, function, style for public space. Public spaces that have been built already should be taken into POE (Post Occupancy Evaluation), Using observation, questionnaires, interviews and other methods to accumulate data and feedback information for the various types of POPs. accumulate data and feedback information and find potential problems and new demand, so that developers benefit while providing an excellent public space for the city.

\section{REFERENCE}

Carmona, M. Magalhaes, C. D. \& Hammond. L.2008. Public space: the management dimension. London: Routledge.

Davis, M. 1992. Fortress Los Angeles: the militarization of urban space. New York: Hill and Wang.

Webster, C. 2007. Property rights, public space and urban design. Town Planning Review.

Kayden, J. S., NYCDCP \& NYMAS. 2000. Privately owned public space. New York: John Wiley \& Sons Inc.

Killian, T. 1998. Public and private, power and space. Lanham: Rowman \& Littlefield Publishers.

Kohn, M. 2004. Brave new neighborhoods: the privatization of public space. New York: Routledge.

Loukaitous Sideris, A. 1996. Cracks in the city: addressing the constraints and potentials of urban design. Journal of Urban Design.

Nemeth, J. 2009. Defining a public: the management of privately owned public space. Urban Studies.

Smithsimon, G. 2008. Dispersing the crowd: bonus plazas and the creation of public space. Urban Affairs Review. 